\title{
Ultrasonographic Assessment of Sternoclavicular Joint in Patient with Rheumatoid Arthritis
}

\author{
Khaled A. Zaki, Hassan M. Bassiouni, Hany M. Aly, Ibrahim E. Elsakka \\ Department of Physical Medicine, Rheumatology and Rehabilitation, Faculty of Medicine, \\ Al-Azhar University, Cairo, Egypt \\ Corresponding author: Ibrahim E. Elsakka; Mobile: 01095772459; Email: ielsakka9@gmail.com
}

\begin{abstract}
Background: the sternoclavicular (SC) joint is a real diarthrodial joint that can be affected during the route of RA; but, its scientific implications appear to remain under estimated through the rheumatology network. In every day clinical practice, traditional radiography is taken into consideration the usual imaging approach for assessing SC joint involvement; unfortunately, it can constitute a problem inside the diagnostic evaluation because it provides little data regarding gentle tissue involvement. Moreover, it's far much less sensitive than different imaging techniques for assessment of bony abnormalities. Computed tomography (CT) is considered the gold widespread for detection of bone erosions at different joint degrees, inclusive of the SC joint, its major disadvantage is associated with ionizing radiation. The value of magnetic resonance imaging (MRI) is remarkable as it allows identification of bone marrow edema, greater-articular abnormalities, disc and cartilage lesions, and synovial membrane involvement. However, its use is regularly constrained due to its high price. Currently, ultrasound (US) is right extensively common imaging approach in each clinical exercise and in rheumatology studies to visualize joints and tender tissues. To date, there is a regular frame of evidence assisting its validity, reliability, and feasibility inside the evaluation of persistent inflammatory arthritis and its higher sensitivity than scientific exam in the analysis of synovitis, enthesitis, and tenosynovitis in these patients.Aim of the Work: this work aimed to describe the prevalence of sternoclavicular (SC) joint involvement and the relationship between clinical and ultrasound (US) findings in patients with rheumatoid arthritis. Patients and Methods: the ethical approval was obtained from the hospital ethical research committee and each patient participated in this study signed in informed consent. The present study was conducted on a hundred and twenty patients; their age ranged from 20 to 50 years. They were categorized into 2 groups a- 60 patients knowns as RA, b-60 normal control subjects. They were recruited from Physical Medicine, Rheumatology and Rehabilitation Department of Sayed Jalal and Al-Hussein, Al-Azhar University Hospitals, during the period from April 2018 to October 2018.Results: ultrasound revealed a high prevalence of sternoclavicular joint involvement in patients with rheumatoid arthritis than clinical findings.

Conclusion: the present study provided US evidence that reveals a higher prevalence of SC joint involvement in patients with RA than in age- and sex-matched healthy controls. US was extra sensitive than medical examination for detecting SC joint involvement in RA. The correlation amongst US synovitis, intraarticular PD and the DAS28 showed that SC joints actively participate within the systemic inflammatory manner of RA. The precise position of US within the assessment of the SC joint in sufferers with RA is but to be mounted firmly in the rheumatologic examination.
\end{abstract}

Keywords: ultrasonographic, sternoclavicular joint, rheumatoid arthritis.

\section{INTRODUCTION}

Rheumatoid arthritis is the prototype inflammatory arthritis, affecting about $1 \%$ of the world's population. Its pathogenesis has not been completely understood. However, there's evidence that the sickness can also involve synovial joints, subchondral bone marrow in addition to intra and extra articular fat tissue, and might cause innovative joint destruction and incapacity. Over the remaining two decades, a large improvement in its prognosis has been completed thanks to new strategies for sickness management, the emergence of recent biologic remedies and higher utilization of traditional diseasemodifying anti-rheumatic drugs ${ }^{(\mathbf{1})}$. The sternoclavicular (SC) joint is a real diarthrodial joint that can be worried during the route of RA; but, its scientific implications appear to remain underestimated through the rheumatology network ${ }^{(2)}$.In daily clinical practice, conventional radiography is considered the standard imaging technique for assessing SC joint involvement (3). Unfortunately, it could constitute a trouble in the diagnostic assessment as it offers little records concerning tender tissue involvement. Moreover, it's far much less sensitive than different imaging strategies for the evaluation of bony abnormalities. Computed tomography (CT) is considered the gold standard for detection of bone erosions at specific joint ranges, including the $\mathrm{SC}$ joint, its major drawback is related to ionizing radiation. Magnetic resonance imaging (MRI) is high-quality as it allows identification of bone marrow edema, more articular abnormalities, disc and cartilage lesions, and synovial membrane involvement. However, its use is frequently restrained due to its high fee ${ }^{4}$. Currently, ultrasound (US) is an extensively regularly occurring imaging technique in each scientific practice and in rheumatology studies to visualize joints and soft tissues. To date, there is a consistent frame of evidence assisting its validity, reliability, and feasibility in the evaluation of 
continual inflammatory arthritis and its higher sensitivity than medical exam in the analysis of synovitis, enthesitis and tenosynovitis in those patients ${ }^{(4)}$.

\section{AIM of the WORK}

The aim of this work was to describe the prevalence of sternoclavicular (SC) joint involvement and the relationship between clinical and ultrasound (US) findings in patients with rheumatoid arthritis.

\section{PATIENTS and METHODS}

The present study was conducted on a hundred and twenty patients, their age ranged from 20 to 50 years. They were categorized into 2 groups: 60 patients knowns as RA, and another 60 normal control subjects. They were recruited from Physical Medicine, Rheumatology and Rehabilitation Department of Sayed Jalal and Al-Hussein Al-Azhar University Hospitals, during the period from April 2018 to October 2018.An approval was obtained from the medical ethics committee of Al-Azhar University before starting this study.

All the patients were informed about the study procedures and a written consent was obtained from all of them.

The subjects were categorized into two groups: group A: 60 patient knowns as RA. Group B: 60 normal control subjects.

\section{Patient's selection}

\section{A) Inclusion criteria for group A and B:}

All patients fulfilled the American College of Rheumatology (ACR) 2010 criteria for diagnosis of RA and ACR criteria for classification of rheumatoid arthritis (1987), Age of patients ranged from 20 to 50 years old.

\section{B) Exclusion criteria:}

Age less than 20 years, Steroid injection for the SC joint in the 4 weeks prior to the beginning of the study, A history of injury, surgery, or an infectious disease process involving the SC joint or the anterior chest wall, The presence of a concomitant chronic inflammatory disease (i.e., psoriatic arthritis, calcium pyrophosphate deposition disease, gout), Diabetes mellitus..

\section{I-Full medical history taking:}

Personal history about, name, age, sex, residence, occupation, marital status, special habits of medical importance, in addition to menstrual history and obstetric history including number of labors and abortions for female patients.

History of present illness included: onset, course and disease duration, constitutional symptoms as fatigue, fever, loss of weight, musculoskeletal manifestations as morning stiffness, joint pain, swelling, redness, hotness and muscle pain or weakness, mucocutaneous manifestations as rash, photosensitivity, alopecia, oral ulcers, Raynaud's phenomena, skin ulcers and splinter hemorrhage, gastrointestinal manifestations as anorexia, epigastric pain, nausea, vomiting, diarrhea and constipation. Renal manifestations as loin pain, hematuria, dysuria, urgency, frequency, polyuria or oliguria, puffiness of the eye lids and swelling of the lower limbs.

Past history: drug therapy, steroids, immunosuppressive therapy (doses and duration of therapy) and drug induced lupus, previous operations or hospitalization, drug allergy and history of blood transfusion.

Family history: family history of RA cases or other autoimmune diseases.

II- Examination: general examination, , examination of scalp, eye and skin, cardiac examination, chest examination, abdominal examination, neuropsychiatric examination and articular examination. All joints were examined as follow: inspection: overlying skin color, muscle wasting, deformity and swelling. Palpation: temperature, tenderness and swelling (soft tissue or effusion). Movement: both active and passive movement was done, with observation of pain, crepitus and protecting muscle spasm, local examination, inspection in sitting position, skin changes such as discoloration, scar or rashes, swelling either generalized or localized.

Palpation: warmth, swelling either generalized or localized, synovial hypertrophy, bony enlargement, crepitus and clicking of the joint with motion.

III-Assessment of the disease activity by using: the DAS28 is a composite score derived from four of these measures. This ' 28 ' version is a simplification of the unique DAS rating, which requires forty four joints to be counted.

Content: count the number of swollen joints (out of the 28), count the number of tender joints (out of the 28), measure the erythrocyte sedimentation rate (ESR) or C reactive protein (CRP), ask (the patient) to make a 'global assessment of health' (indicated by marking a $10 \mathrm{~cm}$ line between very good and very bad).

Score Interpretation: a DAS28 of greater than 5.1 implies active disease, less than 3.2 low disease activity, and less than 2.6 remission

Investigations: Complete Blood Picture (CBC): analyzed using coulter counter (T660).

C-Reactive protein (CRP): assay by Bio-MedCRP latex agglutination method.

Erythrocyte sedimentation rate (ESR): by Westergren method. The reading of first hour was taken. 
Liver function tests: serum ALT, AST by Hitachi Cobas C 311 automated analyzer.

Renal function tests: serum creatinine, blood urea and serum uric acid by Hitachi Cobas C 311 automated analyzer.

Blood sugar: fasting blood glucose and 2hours post prandial blood glucose level by Hitachi Cobas C 311 automated analyzer. Urine analysis: 24hour protein/ in urine: 24-hour urine and spot urine sample was collected to estimate urinary protein excretion. Autoimmune profile: including RF, Anti-CCP were detected by an enzyme-linked immunesorbent assay (ELISA).

\section{Musculoskeletal ultrasound of SC joint The procedure:}

All subjects have been tested with commercially to be had system with the use of $8-12 \mathrm{MHz}$ linear phased array transducer (APLIO400 Model, Toshiba ultrasound machine) the ultrasound system includes a transducer (linear probe) connected to an ultrasound laptop that controls, disk drive, and a printer. The transducer consists of quartz crystals that make use of the piezoelectric impact, which transforms electrical modern-day into sound waves. For each patient and wholesome manage, US examinations covered longitudinal and transverse scans of the SC joint carried out bilaterally, in keeping with a formerly described scanning technique. Briefly, the transducer was positioned parallel and perpendicular to the lengthy axis of the medial clavicle. The SC joint was identified moving the probe medially. The cortical surfaces of the medial clavicle and sternum had been recognized with the hypoechoic joint area between them and this showed the probe position and the respective everyday US photo.Each SC joint turned into first of all scanned in grayscale to stumble on morphostructural modifications and in the end with the power Doppler (PD) approach to locate intra articular synovial blood perfusion. Blood flow assessment was done with settings standardized as follows: pulse repetition frequency $750 \mathrm{~Hz}$, Doppler frequency between 6 and eight $\mathrm{MHz}$, and wall filter out four. PD advantage changed into adjusted to avoid random noise visualization. Synovial PD signal was scored on the basis of the following semi-quantitative scoring: zero $=$ absent (no synovial float), $1=$ slight $(\leq$ three PD signals in the synovial location), $2=$ mild ( $>3$ PD alerts in less than one-half of the synovial region), and three $=$ marked (alerts in a couple of $-1 / 2$ of the synovial location).For US elementary lesions, the Outcome Measures in Rheumatology preliminary definitions were adopted, the following abnormalities were recorded in both groups: synovitis and erosions. synovitis changed into described as the presence of either synovial hypertrophy and/or joint effusion. Synovial effusion became defined as unusual hypo- or anechoic (relative to subdermal fats, however from time to time can be iso- or hyperechoic) intraarticular fabric that is displaceable and compressible, but that does not showcase a Doppler sign. Synovial hypertrophy turned into described as bizarre hypoechoic (relative to subdermal fat, but now and again may be iso- or hyperechoic) intraarticular tissue that is nondisplaceable and poorly compressible, and that can showcase a Doppler sign. Figure (1), Bone erosion turned into described as an intraarticular discontinuity of the bone floor that is visible in 2 perpendicular planes (Figure 2)

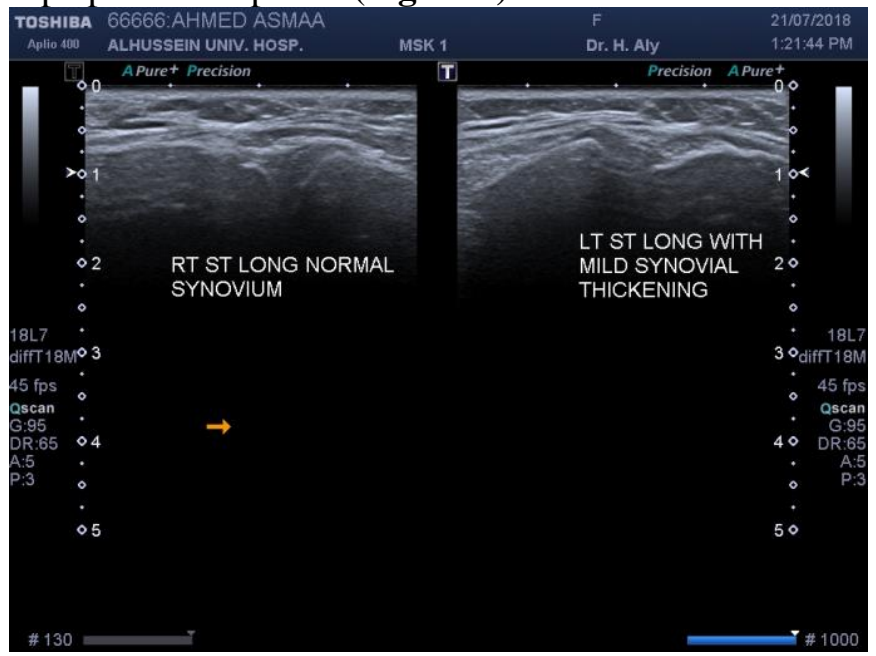

Figure 1: comparison between Rt and Lt normal synovium and mild synovial thickening

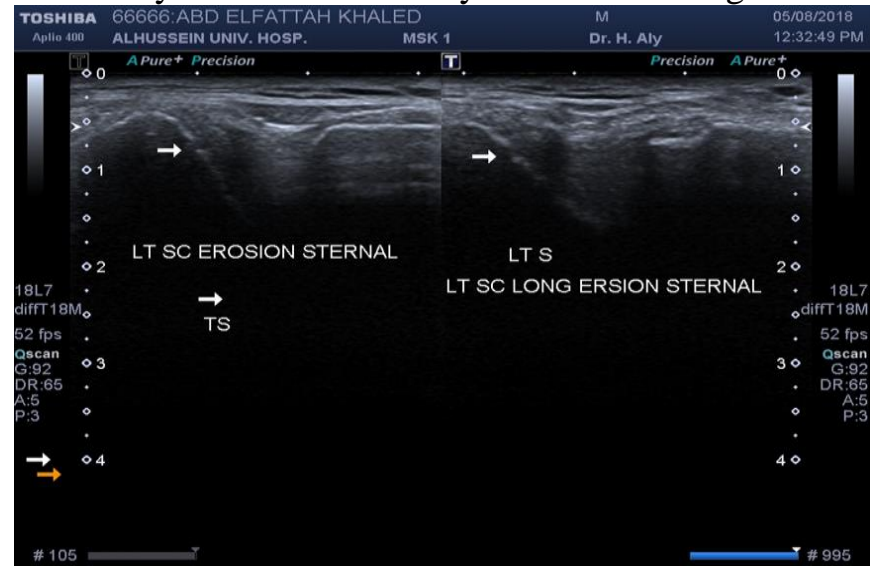

Figure 2: left SC sternal erosion in both longitudinal and transverse scans

\section{Statistical analysis}

recorded data were analyzed by using the statistical package for social sciences, version 20.0 (SPSS Inc., Chicago, Illinois, USA). Quantitative data were expressed as mean \pm standard deviation (SD). Qualitative data were expressed as frequency and percentage.

\section{The following tests were done:}

Independent-samples t-test of significance was used when comparing between two means.Chi-square (x2) test of significance was used in order to compare proportions between qualitative parameters.Binary logistic regression: was used to predict the outcome of categorical variable based on one or more predictor variables.

The confidence interval was set to $95 \%$ and the margin of error accepted was set to $5 \%$. So, the $\mathrm{p}$-value was considered significant as the following: probability $(\mathrm{P}$-value $)=, \mathrm{P}$-value 
$<0.05$ was considered significant . P-value $<0.001$ was considered as highly significant. P-value $>0.05$ was considered insignificant. The confidence interval was set to $95 \%$ and the margin of error accepted was set to $5 \%$. So, the pvalue was considered significant as the following: probability (P-value). P-value $<0.05$ was considered significant. P-value $<0.001$ was considered as highly significant. P-value $>0.05$ was considered insignificant.

\section{RESULTS}

Table 1: comparison between groups according to the demographic data

\begin{tabular}{|c|c|c|c|c|c|}
\hline & Demographic Data & $\begin{array}{c}\text { Group A: Rheumatoid } \\
\text { Arthritis }(n=60)\end{array}$ & $\begin{array}{c}\text { Group B: Control } \\
(n=60)\end{array}$ & $\mathbf{t} / \mathbf{x} 2 \#$ & p-value \\
\hline Sex & $\begin{array}{l}\text { Female } \\
\text { Male }\end{array}$ & $\begin{array}{c}51(85.0 \%) \\
9(15.0 \%)\end{array}$ & $\begin{array}{c}51(85.0 \%) \\
9(15.0 \%)\end{array}$ & $0.000 \#$ & 1.000 \\
\hline $\begin{array}{l}\text { Age } \\
\text { (years) }\end{array}$ & $\begin{array}{l}\text { Mean } \pm \text { SD } \\
\text { Range }\end{array}$ & $\begin{array}{c}42.15 \pm 4.88 \\
31-\mathrm{a} 50 \\
\end{array}$ & $\begin{array}{c}41.97 \pm 6.02 \\
27-\mathrm{a} 49 \\
\end{array}$ & 1.519 & 0.302 \\
\hline
\end{tabular}

\section{I-Demographic data:}

According to the demographic data for the two group A, B, all subjects were Egyptian with age ranged from 20 to 50 years old. For group A; patients with established RA diagnosis according to the ACR Criteria 2010 and 1987 classification criteria for RA. As regard the comparison between the two groups according to demographic data, there was no statistically significant difference between them.

Table 2: comparison between groups according to the clinical data

\begin{tabular}{|l|c|c|c|c|}
\hline Clinical Data & $\begin{array}{c}\text { Group A: } \\
\text { Rheumatoid } \\
\text { Arthritis (n=120) }\end{array}$ & $\begin{array}{c}\text { Group B: Control } \\
(\boldsymbol{n}=120)\end{array}$ & X2 & p-value \\
\hline $\begin{array}{l}\text { Swelling } \\
\text { Yes }\end{array}$ & $19(15.8 \%)$ & $\begin{array}{c}3(2.5 \%) \\
117(97.5 \%)\end{array}$ & 12.811 & $<0.001^{* *}$ \\
\hline No & $101(84.2 \%)$ & $6(5.0 \%)$ & & \\
\hline $\begin{array}{l}\text { Tenderness } \\
\text { Yes } \\
\text { No }\end{array}$ & $21(17.5 \%)$ & $114(95.0 \%)$ & 9.390 & $0.002 *$ \\
\hline
\end{tabular}

As regard the comparison between the two groups according to clinical data there was statistically significant difference between groups according to clinical data.

II- Comparison between groups according to ultrasound findings

\begin{tabular}{|c|c|c|c|c|}
\hline Ultrasound (US) findings & $\begin{array}{l}\text { Group A: Rheumatoid } \\
\text { Arthritis }(n=120)\end{array}$ & $\begin{array}{c}\text { Group B: Control } \\
(n=120)\end{array}$ & $\mathbf{X} 2$ & p-value \\
\hline \begin{tabular}{|l} 
Erosion \\
Yes \\
No
\end{tabular} & $\begin{array}{l}27(22.5 \%) \\
93(77.5 \%)\end{array}$ & $\begin{array}{c}0(0.0 \%) \\
120(100.0 \%)\end{array}$ & 30.423 & $<0.001 * *$ \\
\hline $\begin{array}{l}\text { Synovitis } \\
\text { Yes } \\
\text { No }\end{array}$ & $\begin{array}{l}28(23.3 \%) \\
92(76.7 \%)\end{array}$ & $\begin{array}{c}3(2.5 \%) \\
120(100.0 \%)\end{array}$ & 31.698 & $<0.001 * *$ \\
\hline $\begin{array}{l}\text { Power Doppler } \\
\text { Yes } \\
\text { No }\end{array}$ & $\begin{array}{c}7(5.8 \%) \\
113(94.2 \%)\end{array}$ & $\begin{array}{c}0(0 \%) \\
120(0 \%)\end{array}$ & 4.655 & $0.031 *$ \\
\hline
\end{tabular}

As regard the comparison between the two groups according to ultrasound findings there was statistically significant difference between groups according to ultrasound findings.

Table 4: correlation between duration years with erosion and synovitis in group A: rheumatoid arthritis $(\mathrm{n}=120)$

\begin{tabular}{|c|c|c|c|c|c|}
\hline \multirow{2}{*}{ Ultrasound (US) findings } & \multicolumn{3}{|c|}{ Duration (year) } & \multirow{2}{*}{ t-test } & \multirow{2}{*}{ p-value } \\
\hline & $\mathbf{N}$ & Mean & $\pm \mathrm{SD}$ & & \\
\hline $\begin{array}{l}\text { Erosion } \\
\text { Yes } \\
\text { No }\end{array}$ & $\begin{array}{l}27 \\
93\end{array}$ & $\begin{array}{l}8.93 \\
6.74\end{array}$ & $\begin{array}{l}3.31 \\
2.94\end{array}$ & 3.498 & $0.007 *$ \\
\hline $\begin{array}{l}\text { Synovitis } \\
\text { Yes }\end{array}$ & 28 & 8.96 & 4.34 & 3.150 & $0.002 *$ \\
\hline
\end{tabular}




\begin{tabular}{|l|c|c|c|c|c|} 
No & 92 & 6.72 & 2.54 & & \\
\hline Power Doppler & & & & & \\
Yes & 7 & 8.34 & 3.41 & 2.259 & $0.026^{*}$ \\
No & 113 & 6.87 & 3.09 & \\
\hline
\end{tabular}

As regard the correlation between duration years with erosion and synovitis in group A there was statistically significant relation between duration of years and ultrasound findings (synovitis, erosions).

Table 5: correlation between DAS28 ESR with erosion and synovitis in group A: Rheumatoid arthritis ( $\mathrm{n}=120)$

\begin{tabular}{|l|c|c|c|c|c|}
\hline \multirow{2}{*}{$\begin{array}{l}\text { Ultrasound (US) } \\
\text { findings }\end{array}$} & \multicolumn{3}{|c|}{ DAS28 ESR } & \multirow{2}{*}{ t-test } & \multirow{2}{*}{ p-value } \\
\cline { 2 - 4 } & $\mathbf{N}$ & Mean & $\mathbf{\pm S D}$ & & \\
Erosion & & & & & \\
Yes & 27 & 5.48 & 0.77 & \multirow{2}{*}{4.824} & $<0.001^{* *}$ \\
No & 93 & 4.24 & 1.26 & & \\
\hline Synovitis & 28 & 5.61 & 0.86 & & \\
Yes & 92 & 4.19 & 1.19 & 5.846 & $<0.001 * *$ \\
No & & & & & \\
\hline Power Doppler & 7 & 5.88 & 0.75 & 2.997 & $<0.001^{* *}$ \\
Yes & 113 & 4.44 & 1.25 & & \\
No & & & & \\
\hline
\end{tabular}

As regard the correlation between DAS28 ESR with erosion and synovitis in group A: there was statistically significant relation between DAS28 ESR with erosion and synovitis.

Table 6: comparison between ultrasound (US) "SC" and clinical data (Swelling and tenderness) in group A: rheumatoid arthritis $(\mathrm{n}=120)$

\begin{tabular}{|l|c|c|c|c|}
\hline $\begin{array}{l}\text { Group A: } \\
\text { Rheumatoid } \\
\text { Arthritis }(\boldsymbol{n}=120)\end{array}$ & $\begin{array}{c}\text { Ultrasound } \\
\text { (US) findings } \\
\text { (SC) }\end{array}$ & $\begin{array}{c}\text { Clinical Data } \\
\text { (Swelling \& } \\
\text { Tenderness) }\end{array}$ & X2 & p-value \\
\hline $\begin{array}{l}\text { Erosion } \\
\text { Yes }\end{array}$ & $\begin{array}{l}27(22.5 \%) \\
93(77.5 \%)\end{array}$ & $\begin{array}{c}15(12.5 \%) \\
105(87.5 \%\end{array}$ & 4.899 & $0.027 *$ \\
\hline No & $28(23.3 \%)$ & $17(14.2 \%)$ & & \\
\hline $\begin{array}{l}\text { Synovitis } \\
\text { Yes }\end{array}$ & $92(76.7 \%)$ & $103(85.8 \%)$ & 5.492 & $0.037 *$ \\
\hline $\begin{array}{l}\text { Power Doppler } \\
\text { Yes }\end{array}$ & $7(5.8 \%)$ & $\begin{array}{c}4(3.3 \%) \\
116(96.7 \%)\end{array}$ & 0.381 & 0.537 \\
\hline No & $113(94.2 \%)$ & & & \\
\hline
\end{tabular}

As regard the comparison between ultrasound (US) "SC" and clinical data (swelling \& tenderness) there was statistically significant difference) in group A

Table 7: correlation between clinical data (Swelling and tenderness) and ultrasound findings in group A: Rheumatoid arthritis $(\mathrm{n}=120)$

\begin{tabular}{|c|c|c|c|c|c|c|c|}
\hline \multirow{3}{*}{$\begin{array}{l}\text { Ultrasound } \\
\text { (US) findings }\end{array}$} & \multicolumn{4}{|c|}{$\begin{array}{c}\text { Clinical Data (Swelling \& } \\
\text { Tenderness) }\end{array}$} & \multicolumn{3}{|c|}{ Odds Ratio } \\
\hline & \multicolumn{2}{|c|}{ Presence } & \multicolumn{2}{|c|}{ Absence } & \multirow{2}{*}{ OR } & \multirow{2}{*}{$\begin{array}{l}\text { C.I. } \\
\text { 95\% }\end{array}$} & \multirow[b]{2}{*}{ p-value } \\
\hline & No. & $\%$ & No. & $\%$ & & & \\
\hline $\begin{array}{l}\text { Erosion } \\
\text { Yes } \\
\text { No }\end{array}$ & $\begin{array}{c}15 \\
0\end{array}$ & $\begin{array}{c}100.0 \% \\
0.0 \%\end{array}$ & $\begin{array}{l}12 \\
93\end{array}$ & $\begin{array}{l}11.4 \% \\
88.6 \%\end{array}$ & 0.444 & $\begin{array}{c}0.292- \\
0.678\end{array}$ & $<0.001 * *$ \\
\hline $\begin{array}{l}\text { Synovitis } \\
\text { Yes } \\
\text { No }\end{array}$ & $\begin{array}{c}16 \\
1\end{array}$ & $\begin{array}{c}94.1 \% \\
5.9 \%\end{array}$ & $\begin{array}{l}12 \\
91\end{array}$ & $\begin{array}{l}11.7 \% \\
88.3 \%\end{array}$ & 12.143 & $\begin{array}{l}4.739- \\
98.839\end{array}$ & $<0.001 * *$ \\
\hline $\begin{array}{l}\text { Power } \\
\text { Doppler } \\
\text { Yes } \\
\text { No }\end{array}$ & $\begin{array}{l}4 \\
0\end{array}$ & $\begin{array}{c}100.0 \% \\
0.0 \%\end{array}$ & $\begin{array}{c}3 \\
113\end{array}$ & $\begin{array}{c}2.6 \% \\
97.4 \%\end{array}$ & 0.429 & $\begin{array}{c}0.182- \\
1.008\end{array}$ & $<0.001 * *$ \\
\hline
\end{tabular}


As regard the correlation between clinical data (Swelling and tenderness) and ultrasound findings there was statistically significant relation between clinical data and ultrasound findings.

\section{DISCUSSION}

In a study done by Rizoo et al. ${ }^{(5)}$ they
indicated that musculoskeletal (MS) ultrasonography (US) underwent exceptional technological improvement of equipment with improved sensitivity in detecting a broad set of joint and soft tissues abnormalities, In RA MSUS with the usage of Doppler modalities is a beneficial imaging device to depict inflammatory abnormalities (i.e., synovitis, tenosynovitis and bursitis) and structural adjustments (i.e., Bone erosions, cartilage damage and tendon lesions).

Iagnocco et al. ${ }^{(1)}$ determined the method included using grayscale (GS) imaging and Doppler modalities. GS photographs the anatomic systems and Doppler shows blood flow. Their use is indicated for the assessment of peri- and intraarticular systems, offering an accurate depiction of tender tissue and bony cortex modifications in any respect levels of the disease.

Rodri'Guez et al. ${ }^{(2)}$ stated in their study that SC joint was frequently overlooked throughout routine rheumatologic examinations despite its synovial membrane lining and biomechanical properties as part of the shoulder joint complex. This joint should be carefully examined because it is clinically involved in nearly one third of the most common arthritides.

Rodri'Guez et al. ${ }^{(2)}$ found in their study that at least 1 US elementary lesion suggestive of $\mathrm{SC}$ joint involvement was recorded in $89 \mathrm{SC}$ joints $(43 \%)$ in the RA group compared with $36 \mathrm{SC}$ joints $(17 \%)$ in the healthy control group; therefore, US assessment showed significantly higher SC joint involvement in patients with RA than in healthy controls. In our study it was found that SC joint involvement in $62 \mathrm{SC}$ joints was (51.6\%) in the RA group compared with $120 \mathrm{SC}$ joints $(2.5 \%)$ in the healthy control group; therefore, US assessment showed significantly higher SC joint involvement in patients with RA than in healthy controls. Our study provided evidence about a higher number of involved SC joints than in clinical assessment in patients with RA. Moreover, our results indicate that both gray-scale and PD findings were more prevalent in patients with RA than in age- and sex-matched healthy controls. In the view of the abovementioned information, our result indicated that Urinary CD4 T-cells marker has a valuable role in detecting LN in SLE patients and has significant correlation with disease activity index. Our study provided evidence about a higher number of involved SC joints than in clinical assessment in patients with RA. Moreover, our results indicate that both gray-scale and PD findings were more prevalent in patients with RA than in age- and sex-matched healthy controls. Also, these results are in accordance with Rodri'Guez et al. ${ }^{(2)}$ who concluded that in patients with RA, US detected a higher number of involved SC joints than with clinical assessment and indicated that both gray-scale and PD US findings were more prevalent in patients with RA than in healthy controls.US synovitis and synovial hyper perfusion correlated with the DAS28, suggesting that SC joints actively participate in the systemic inflammatory process of RA.

\section{CONCLUSION}

The present study provided US evidence that reveals a higher prevalence of SC joint involvement in patients with RA than in age- and sex-matched healthy controls. US was extra sensitive than medical examination for detecting SC joint involvement in RA. The correlation amongst US synovitis, intraarticular PD, and the DAS28 showed that SC joints actively participate within the systemic inflammatory manner of RA. The precise position of US within the assessment of the SC joint in sufferers with RA was mounted firmly in the rheumatologic examination.

\section{REFERENCES}

1-Sudol-Szopińska I, Jans $\mathrm{L}$ and Teh J (2017): Rheumatoid arthritis: what do MRI and ultrasound show . Journal of ultrasonography, 17(68):5-10.

2-Rodríguez-Henríquez $\mathbf{P}$, Solano $C$, Peña A, León-Hernández S et al. (2013): Sternoclavicular joint involvement in rheumatoid arthritis: clinical and ultrasound findings of a neglected joint. Arthritis Care and Research, 65(7): 1177-1182.

3-Guglielmi G, Cascavilla A, Scalzo G, Salaffi F and Grassi W (2009): Imaging of sternocostoclavicular joint in spondyloarthropaties and other rheumatic conditions. Clinical and Experimental Rheumatology,27(3):402-409.

4-Filippucci E, Annamaria I, Meenagh G, Riente L, Delle Sedie A, Bombardieri S and Grassi W (2006): Ultrasound imaging for the rheumatologist II. Ultrasonography of the hand and wrist. Clinical and Experimental Rheumatology, 24(2):118-122. 
5-Rizzo C, Fulvia C, Angelica G, Vavala C, Guido V and Annamaria I (2013): Ultrasound in rheumatoid arthritis. Medical Ultrasonography,15(3):199-208.
6-Iagnocco A, Ceccarelli F, Perricone C and Valesini G (2011): The role of ultrasound in rheumatology. In: Seminars in Ultrasound, CT and MRI. WB Saunders.London.pp:66-73. 